\title{
Long-lived granulite-facies metamorphism in the North China Craton constrained by combined garnet and zircon geochronology
}

\author{
KAI-YANG DU ${ }^{1}$, HAO CHENG $^{2}$ \\ ${ }^{1}$ State Key Laboratory of Marine Geology, Tongji \\ University, Shanghai 200092, China \\ dukaiyang@tongji.edu.cn \\ ${ }^{2}$ State Key Laboratory of Marine Geology, Tongji \\ University, Shanghai 200092, China \\ chenghao@tongji.edu.cn
}

Zircon geochronology of high-temperature metamorphic rocks, in particular granulite-facies rocks, provides critical constraints on the timing of relevant tectonometamorphic processes, however, readily yields spread results, limiting the resolution of closely spaced events. Garnet is crucial for constraining tectonic processes because its composition can be used to provide $P-T$ constraints and both the $\mathrm{Lu}-\mathrm{Hf}$ and $\mathrm{Sm}-\mathrm{Nd}$ isotopic systems can be employed to provide age constraints using the same sample aliquots. Nevertheless, garnet $\mathrm{Lu}-\mathrm{Hf}$ and $\mathrm{Sm}-\mathrm{Nd}$ geochronology may not yield the same dates for a particular rock or a single grain due to mixture of different generational or differential isotope reequilibration of the dated phase. This decoupling is presumably strong in high-temperature and long-lived metamorphic rocks, which may potentially be used to estimate the duration of the growth/cooling history of garnet and the associated tectonic processes because of their different closure temperatures. A combined zircon and garnet multi-petrochronology approach is crucial to yield reliable interpretation of geochronological data in the context of the $P-T$ history, essential to decipher the tectonometamorphic evolutions.

Here we report metamorphic $P-T$, garnet $\mathrm{Lu}-\mathrm{Hf}$ and $\mathrm{Sm}-$ $\mathrm{Nd}$ dates, and zircon $\mathrm{U}-\mathrm{Pb}$ dates for four granulite-facies metamorphic rocks from the North China Craton. Pseudosection modelling defines the peak $P-T$ conditions of approximately $1.0 \mathrm{GPa}$ and $780-870{ }^{\circ} \mathrm{C}$ for two mafic granulites. Lu-Hf dates range from $c a .1945$ to $c a$. $1815 \mathrm{Ma}$, while $\mathrm{Sm}-\mathrm{Nd}$ dates, determined on the same aliquots, span from $c a$. 1845 to $c a$. $1780 \mathrm{Ma}$. Lu-Hf dates from each sample are consistently older than the corresponding $\mathrm{Sm}-\mathrm{Nd}$ dates. The zircon U-Pb dates spread from $c a .1998 \mathrm{Ma}$ to $c a .1785$ Ma. The large discrepancy in zircon and garnet dates is interpreted as reflecting the differential closure of the three isotopic systems, reflecting protracted granulite-facies metamorphic processes. 